Удк 316.733:316.325

\title{
О ПРИРОДЕ «КУЛЬТУРНОГО СДВИГА» В СИСТЕМЕ ЦЕННОСТЕЙ КРЕАТИВНОГО КЛАССА В БЛАГОПОЛУЧНОМ ОБЩЕСТВЕ
}

\author{
Кривовяз Наталья Викторовна, \\ awatanchik@yandex.ru \\ Рябченко Даниил Олегович, \\ rd@latat.org \\ Национальный исследовательский Томский политехнический университет, \\ Россия, 634050, г. Томск, пр. Ленина, 30
}

Кривовяз Наталья Викторовна, кандидат экономических наук, доцент Школы инженерного предпринимательства Национального исследовательского Томского политехнического университета.

Рябченко Даниил Олегович, аспирант Школы инженерного предпринимательства Национального исследовательского Томского политехнического университета.

Исследована природа креативного класса, основания и предпосылки «культурного сдвига» в пространстве ценностного мира креативного класса. Проанализированы условия и тенденции формирования системы постматериалистических ценностей (самовыражение, благополучие, счастье), характерных для системы ценностного мира, креативного класса. Раскрыта роль инноваций как креативного разрушения. Заявлена идея возможности измерения креативности в условиях, основанных на знаниях и инновациях экономического роста. В статье анализируется природа "смещения» - «тектонических сдвигов», произошедших в сегментах власти и управления на пороге ХХІ в. Установлена приоритетная роль знания в обозначенных трансформациях как статуса доминирующего ресурса когнитивного общества. Представлена идея формирования «интеллектуальной элиты» когнитивного общества; признаки элитарности формируются как определяемые владением знанием. Показано, что в границах институтов, связанных с интеллектуальной деятельностью, «новой элите» принадлежит монополия на власть и управление. Однако в мире большой политики можно говорить лишь о влиянии «новой элиты» в сегментах экспертизы, консалтинге, процедуре анализа технически сложных решений.

Ключевые слова: Креативная экономика, креативность, креативность как капитал и товар, измерение креативности, постматериалистические ценности, инновации, «культурный сдвиг», этос креативного класса, «эффект постдефицита», ценности выживания, ценности самовыражения, жизненный мир креативного класса, императивы инновационной эпохи.

В последнем десятилетии XX в. мир заговорил о феномене креативной экономики, о появлении экономических систем, стимулирующих творческий потенциал человека. В вопросах оценки положения региона в креативной экономике был введен так называемый Индекс креативности, включающий базовые показатели оценки. При этом обнаружили себя две тенденции, названные аналитиками господствующими. Одна из этих тенденций говорит о возникновении регионов, становящихся центрами креативности (в то время как в других регионах преобладает население, представляющее рабочий или обслуживающий классы). Безусловно, так было всегда - всегда существовали культурные колонии (Гринвич-Вилиндж), университетские (Мэдисон, Боулдер), производственные центры (Питтсбург, Детройд), однако никогда ранее это преобладание не было настолько распространенным явлением. Что касается второй тенденции, ее смысл 
заключен в лидерство креативных агрегаций в совокупности экономических параметров $[1,2]$. Аналитики, исследуя систему перехода к креативной экономике, обратили внимание на сопровождающее этот процесс явление, - им оказалось формирование нового класса, обозначенного как креативный класс креативной эпохи. Спустя десятилетие после первых упоминаний о креативном классе вышло в свет монографическое исследование профессора Школы общественной политики Университета Дж. Мэйсона (Вашингтон) Ричарда Флориды. Исследованию был предпослан интригующий заголовок - «Креативный класс: люди, которые меняют будущее». Вскоре после выхода журналом Harward Business Review книга Р. Флориды была названа «одной из лучших инновационных идей». Аналитики заговорили о появлении нового общественного класса, о креативности как капитале и товаре эпохи инноваций; было обращено особое внимание на феномен численного роста креативного класса, на креативность как исключение конкурентных преимуществ и товар новой креативной экономики [3]. В предмет исследования было превращено измерение креативности, характерное для экономики, основанной на знании и инновациях. И в силу того, что новый класс был выделен на базе экономики, креативность была объявлена движущей силой экономического развития, сам же креативный класс занял в обществе лидирующие позиции. Особенности креативного класса, как писали многие аналитики, определены творческой функцией представителей этого сегмента, а креативная деятельность для входящих в креативный класс была воспринята как решающий фактор деятельности $[4,5]$. Знание названо оружием и рабочим материалом креативности, продуктом креативности стала инновация (по образному определению Й. Шумпетера, именно инновация в условиях креативной экономики обрела статус и новую роль «креативного разрушителя»). Так, интерпретируя свою роль и назначение, инновация проявилась через формы новых технологий, новые формы социальности, новые формы бизнеса, наконец, через инновационнооформленные проявления научных и художественных практик и экономический рост в условиях креативной экономики. Исследующие эту проблему объясняют это с помощью концепции так называемого «3 Т-развития» (технология, талант, толерантность). Для центров сосредоточения креативного класса любой из обозначенных факторов обнаруживает свою значимость, но только единство и очевидность общей представленности этих элементов способны явиться средством привлечения представляющих креативный класс, генерации инноваций и экономического роста, раскрытия новых идей [6].

Р. Флорида в монографическом исследовании «Креативный класс: люди, которые определяют будущее» показывал, как работает концепция 3 Т-развития применительно к университетским центрам, в которых университеты играют роли, воплощающие $3 \mathrm{~T}$ креативных центров - технологии, талант, толерантность [3].

Технология. Университеты выступают центрами передовых исследований в целом ряде областей, от программного обеспечения до биотехнологии, и являются важными источниками новых технологий и их коммерческих внедрений.

Талант. Университеты обладают поразительным свойством притягивать талантливых людей как магнит. Привлекая ведущих исследователей и ученых, университеты тем самым мотивируют аспирантов, генерируют создание научно-практических предприятий и коммерческих компаний, которые размещаются поблизости, создавая самовоспроизводящийся цикл роста.

Толерантность. Университеты способствуют созданию прогрессивного, открытого и терпимого человеческого климата, помогающего привлекать членов креативного класса. 
Именно единством обозначенных 3 Т-факторов, индексами технологий, талантов, толерантности обусловлено расширение культурных горизонтов региона, в котором существуют университетские центры. Основанием исследовательского интереса к феномену креативного класса явился и очевидный рост его численности в развитых странах. К примеру, в США креативный класс насчитывает 38 млн представителей - это более $30 \%$ рабочей силы США [7, 8].

Отражением подъема, переживаемым креативным классом, начиная с первых десятилетий XXI века, стало явление так называемого «культурного сдвига», наблюдаемого в системе ценностей обозначенного класса (понятие класса как социального субъекта предполагает структурное оформление на платформе общеразделяемых ценностей). Ценности всегда играют роль катализаторов, - именно они обеспечивают интеграцию и устойчивость такой социальной общности, как класс [9]. При этом важен процессуальный аспект формирования ценностей. Понятие «ценность» употребляется по отношению к различным видам селективных ориентаций, - в ценностях находят отражение интересы, предпочтения, обязанности, моральные обязательства, желания, цели, потребности (позиция Р. Вильямса) [10]. В системе ценностей объединены общие представления, критерии оценок, предпочтений, моделей поведения. Н. Лосскому принадлежит взгляд на ценность как феномен, связанный со способностью субъекта придавать смысл и определять его, - для мира в целом, для личности, для каждого события и каждого поступка. В этом смысле ценности могут быть интерпретированы как квинтэссенция смысла, как то, что придает целостность духовному существованию личности. Р. Вильямсом выделены такие аспекты ценностей, как оценочный, критериальный (ценность выступает как некий стандарт, положенный в систему оценки, исходя из чего субъектом оправдывается выбор линии поведения) [11]. В теории Т. Парсона ценностям придан статус элементов общепринятой символической системы в качестве критерия или стандарта, используемой при выборе изменяющихся альтернатив ориентации. Понимаемые таким образом ценности играют роль компонентов культурных моделей и традиций; сама же система культуры представлена как нормативная. В структуре ценностных ориентаций Т. Парсон выделяет такие аспекты, как оценочный (он определяет выбор из ряда альтернатив через определение значимости объекта), когнитивный (он направлен на познание объекта через соотнесение с потребностями и интересами) и катектический (определяющий желательность), что выражено в реагировании на объект как соответствующий удовлетворению либо неудовлетворению [12]. На роль ценности в обосновании интересов указывает А.Г. Здравомыслов, связь ценностей и интересов отражена также в концепциях Г. Олпорта, Ф. Вернона, Г. Линдзи. Авторы делают акцент на динамике формирования ценностей: обретая независимое и потребность существования, система ценностей превращается в автономный ориентир поведения личности. Наконец, операциональное определение ценностей предложено М. Рокичем («Природа человеческих ценностей»). Система ранжирования, предлагаемая автором, строится на представлении о терминальных ценностях (конечные цели, конечные основания целеполагания, представления о «высшем благе») и инструментальных (средство достижения цели, т. е. убеждения в большей предпочтительности избираемого образа действий). Терминальные ценности - высший, доминирующий уровень иерархической системы ценностей. Инструментальные же ценности значимы лишь в роли структуры реализации целевых ценностей. И система социальных связей - это не структура, это поле, имеющее то «стягивающее ядро» (П. Штомпка), которое определено ценностями [13]. 
Эволюция креативного класса обнаружила себя уже в 1960-е гг. и нашла отражение в работах П. Друкера и Ф. Махлупа, где авторы назвали входивших в новую профессиональную группу «работниками интеллектуального труда». Десятилетие спустя Д. Белл описал иную меритократическую структуру (ученые, инженеры, представители менеджариальных групп); Э.-О. Райтом введено понятие «профессиональноадминистративного класса» [14]. Вошел в обиход и термин «символической аналитики». Анализирующие проблемы формирующейся классовой структуры обратились к исследованию нового этоса - этоса креативного класса, описанного в 1983 г. Полом Расселом в монографии «Класс». Нетипичность и оригинальность, независимость мышления - все это черты тех, кто представляет креативный класс [15].

Как пишет Р. Флорида, в определении класса он делал акцент на способах самореализации субъектов в социальных группах на общей идентичности, в основании которой - экономическая функция представляющих креативный класс. Этой функцией определены разнообразие, скрытость, несогласие с организационными нормами, интересы, социальные и культурные предпочтения, социальная идентичность субъектов креативного класса. «Члены креативного класса обычно не владеют какой-либо существенной собственностью в материальном смысле. Их собственность, проистекающая из творческих способностей, не имеет физической формы, поскольку располагается буквально у них в мозгу. Мои практические исследования и интервью делают все больше свидетельств тому, что, если представители креативного класса пока не рассматривают себя в качестве единой общественной группировки, в реальности их объединяют общие вкусы, желания и предпочтения» [3].

Система ценностей нового класса претерпела значительные трансформации. Это выразилось во введенных социологами понятиях «сдвиг ценностей», «эффект постдефицита», «креативная идентичность», «индивидуальная тождественность». Исследования Э. Рейха, С. Барли, С. Бринта, Д. Брукса - обзор присущей креативному классу системы ценностей, представленный группой социологов Мичиганского университета (руководителем ряда проектов был Р. Инглхарт). Данные исследования говорят о совершенном отходе от целого ряда ценностей, о сдвиге от проблем экономического роста к ценностям, связанным с образом жизни (от ценностей «выживания» к ценностям «самовыражения») [16, 17]. Эпоха наступившего «постдефицита» трансформировала иерархию приоритетов в системе ценностей, это нашло отражение во внимании к категориям «образ жизни», «качество жизни» и «формирование жизненного мира креативного класса», в которых предпочтение отдается так называемым постматериалистическим ценностям - ценностям самовыражения благополучия, счастья. Как отмечает Р. Флорида, обращаясь к идее «разрыва поколений», культурный сдвиг в системе ценностей возможен и реален только для тех поколений и классов, которым гарантирована физическая безопасность и экономическая стабильность. Субъект этой новой общности креативного класса, формируемого императивами инновационной креативной эпохи, Homo creations, производящий экономические ценности в процессе творчества [18].

Сферы власти и управления в ситуации происходящих сдвигов оказываются насыщаемыми так называемым информационным знанием. Что свидетельствует об этом? Мы видим артефакты этого в том, что под влиянием трансформаций, совершающихся в производственной и непроизводственной сферах, доминирующая доля занятых переходит в сегмент работы с информацией, ее сбора, обработки. И если традиционно эта деятельность рассматривалась как непроизводительная, сегодня она превращена в условие новой системы, что в свое время предвидели Д. Белл, О. Тоффлер, З. Бжезинский, Дж. Гэлбрайт, использовав понятие «сдвиг власти». Знание и информация обрели 
статус стратегических ресурсов власти и управления. Непроизводственная сфера оказалась приоритетной, властвующей. Изменилась природа собственности и капитала - их место заняла информация, знание стало капиталом. Власть и управление реализуют себя посредством интеллекта. Интеллект и капитал властно заявляют о себе в общем социокультурном развитии, находят свое воплощение в «суперсимволической экономике», «символическом обмене», информационных сетях, «электронных деньгах». В этом же плане сказалось и влияние формирующихся информационных технологий.

Властная роль знания меняет и интерпретацию труда. Возникло понятие интеллектуального труда, к которому отнесены сбор и передача информации, научные исследования, программирование, проектирование. Как результат, меняются социальная структура и формы занятости; растет уровень интеллигенции, появляются профессионалы «технического класса». В середине XIX в. К. Маркс характеризовал «умственный труд» как «непродуктивный», но на рубеже XX-XXI вв. этот труд явил собой проблему первостепенной важности для перехода к информационной экономике. Благодаря подобному труду и механизму его обеспечения, общества с высокими технологиями вошли в разряд наиболее развитых, компьютеризованный капитализм, а неиндустриальный социализм стал предсказанным К. Марксом «качественным скачком вперед». В этом же плане следует рассматривать и возникновение новых инновационных стадий развития информационного общества. Пролетариат, бывший ведущей стратой общества индустриального, оказавшись занятым работой со знанием, превращается в «когнитариат» [19]. Знание создало необходимость появления новой формы капитала - человеческого капитала, который стал важнейшим ресурсом общества. Человеческий капитал занял место традиционно основных способов роста национального богатства. Наука и прогрессивные технологии, освоенные человеком, или человек, владеющий научным знанием, - сегодня именно это, в отличие от прошлых этапов социокультурной истории, создает условия для развития. Опытность технических и гуманитарных экспертов, компетентность управляющего персонала и квалифицированность рабочей силы превращены в новую социокультурную основу для появления страты, получившей название когнитариата. Появление этой страты явилось свидетельством того, что информация, знание и технологии превращены в доминирующие факторы национального роста, само же общество создало ситуацию, когда любой вид деятельности содержит информационную компоненту. Стоимость становится результатом умственного труда и информации.

В заключение отметим, что принципиальное изменение природы власти обуславливает ее смещение в сторону роста во властных структурах факторов интеллекта и знания. Знание, ставшее властью, меняет ее характер, содержание и функции. Устраняется сакральность, формируется открытость и демократичность; знание, обретая функцию власти, является ресурсом власти. Предпосылки необходимости соединения знания и власти в обществе знания стали явными. Вопрос, ранее поставленный как гносеологический, получил социальное звучание. Современность расширила область применения знания в его управленческом значении: из сферы государственного, политического управления оно перешло во все социальные инфраструктуры. Управление - как государственное, так и негосударственное - в равной степени требует работы власти только на основе знания. В основание стратегий управления когнитивного общества заложены два доминирующих принципа - принцип управления процессами создания массивов применяемых знаний и принцип управления происходящими в обществе изменениями. В основу последних также положено знание. 
Современность переосмысливает знание как гносеологическую категорию, сообщая знанию социокультурную проблематизацию. В сегментах социальности и культуры знание и обретает характер и смысл источника власти и управления.

На рубеже XX-XXI вв. в обход теории управления прочно вошел термин стратегии управления знаниями - термин, чрезвычайно важный для процесса управления, основанного на знании. Т. Андреева [20] определяет управление знаниями как создание уникальной организационной архитектуры, посредством которой выявляется неявное, оценивается бесценное, распространяется актуальное, сохраняется текущее, забывается устаревшее. Знание превратилось в ценнейший стратегический ресурс, проблема же сохранения конкурентоспособности сформировала интенсивную потребность в программах и проектах управления знаниями. Авторы этих программ и проектов сосредоточили внимание на важнейших для когнитивного менеджмента сегментах проблемы управления знанием как важнейшим ресурсом когнитивного общества. Среди этих проблем - знание как основа конкурентного преимущества (И. Нонака, Л. Арготэй, П. Инграм), природа научающейся организации (Д. Гарвин), практики управления знанием и управление организационным забыванием (А. Дагфуз); специфика и природа формирования знаниевых стратегий (М.-Х. Зак), управление профессиональным интеллектом (Д. Куинн, Ф. Андерсон, С. Финкельштейн), диагностика культурных барьеров в управлении знаниями (Д.-У. Делонг, Л. Фейхи), организационные механизмы создания знаний (И. Нанака, Н. Конно), модели, используемые для измерения интеллектуального капитала (Т. Дейвенпорт, Н. Бонтис, Д.-У. Демонт), работа со знанием как форма организационного поведения (И. Келлоуэй, Дж. Барлинг, К. Арджирис, М. Глисби, Н. Олден), концепция «хранилищ знаний» (Л. Арготей, П. Инграм). Большинство из упомянутых проблем, будучи положены в основу программ и проектов, ориентированных на управление знанием, требуют для своего решения эвристических возможностей междисциплинарного подхода. Именно междисциплинарный подход позволяет в итоге достичь организационных целей через наиболее эффективное использование знаний. Огромна роль в создании обозначенных программ философии, выступающей в значении теории всеобщего и участвующей в определении методологических скреп проектов, структура которых включает в числе необходимых блоков блок инженерии знаний (knowledge engineering), экономического и стратегического управления и блок, посвященный организационным и «человеческим» аспектам управления знаниями.

Разработка аналитических инструментов управления знаниями строится на тезисе о единстве управления знаниями и стратегии организации, при этом важно различать знаниевую стратегию (это конкурентная стратегия, выстроенная вокруг интеллектуальных ресурсов организации) и стратегию управления знаниями (это стратегия, определяющая процессы и инфраструктуру для управления знаниями).

Четко понимая стратегические приоритеты, можно выделить и превратить в приоритетные отдельные аспекты управления через наиболее эффективное использование знаний, совершенствуя классические и создавая новые максимально результативные концепции и модели управления.

\section{СПИСОК ЛИТЕРАТУРЫ}

1. Коллинс Джим. От хорошего к великому. Почему одни компании совершают рывок, а другие нет. М.: Манн, Иванов и Фербер, 2014. - 384 с.

2. Collins J. How the mighty fall: and why some companies never give in. - New York: Jim Collins, 2009. $240 \mathrm{p}$.

3. Флорида Р. Креативный класс: люди, которые меняют будущее. - М.: Классика-ХХІ, 2007. - 421 с. 
4. Занковский А.Н. Организационная психология. - М.: Форум, 2009. - 646 с.

5. Петренко В.Ф. Многомерное сознание. Психосемантическая парадигма. - М.: Новый хронограф, 2009. - $440 \mathrm{c}$.

6. Эндрувайт Г. Элиты и развитие: теория и исследования влияния элит на процессы социальнополитического развития // Политическая наука. Элиты в сравнительно-исторической перспективе. Проблемно-тематический сборник. - М., 1998. - С. 10-11.

7. Clarkin L., Holmes J. Enterprise Mashups. URL: http://msdn.microsoft.com/en-us/architecture/bb906060 (дата обращения: 11.01.2021).

8. Roman F., Peterson M., Koster A. The rise of Generation C: how to prepare for the connected generation's transformation of the consumer and business landscape. - NY.: Strategy + Business, 2011. -8 p.

9. Занковский А.Н. Психология лидера: от поведенческой модели к культурно-ценностной парадигме. М.: Изд-во института психологии РАН, 2011. - 295 с.

10. Мацумото Д. Человек, культура, психология. - СПб.: Прайм-Еврознание, 2010. - 647 с.

11. Вильякайнен П., Мюллер-Эберстайн М. Без страха. Лидеры бизнеса в цифровую эпоху. - М.: ОлимпБизнес, 2015. - 400 с.

12. Тамбиянц Ю.Г., Шалин В.В., Феномен политической элиты: проблематика определения социальной сущности // Общество и право. - 2018. - № 4 (66). - С. 159-164.

13. Зоткин А.А. Подходы к определению понятия «элита» в работах представителей макиавеллистской школы теории элит // Ученые записки Крымского федерального университета имени В. И. Вернадского Социология. Педагогика. Психология. - 2005. - Т. 1 (67). - № 4. - С. 3-12.

14. Bassin M., Glebov S., Laruelle M. Between Europe and Asia: the origins, theories, and legacies of Russian Eurasianism. - Pittsburgh: University of Pittsburgh Press, 2015. - 288 p.

15. Аль-Двани М.Ф.Х. Ценностные основания теории элит // Вестник СПбГУ. - 2014. - Сер. 12. Вып. 2. - С. 146-151.

16. Елин С.П. Критерии элитности в ценностном направлении развития теории элит // Теория и практика общественного развития. - 2014. - № 10. - С. 37-40.

17. Boynton Andy, Bill Fischer, Bill Bole. The idea hunter: how to find the best ideas and make them happen. San Francisco, CA: Jossey-Bass, 2011. - 192 p.

18. Grossman L. 2045: the year man becomes immortal. URL: https://ru.scribd.com/document/50201914/2045The-Year-Man-Becomes-Immortal (дата обращения 11.01.2021).

19. Зак М.Х. Разработка знаниевой стратегии // Управление знаниями. Хрестоматия. - СПб.: Высшая школа менеджмента, 2008. - С. 189-204.

20. Андреева Т.Е. Работник интеллектуального труда: подход к определению // Вестник СанктПетербургского университета. Менеджмент. - 2007. - № 4. - С. 32-49.

Поступила 20.01.2021 г. 
UDC 316.733:316.325

\title{
ON THE NATURE OF «CULTURAL SHIFT» IN THE VALUE SYSTEM OF THE CREATIVE CLASS IN A PROSPEROUS SOCIETY
}

\author{
Natalia V. Krivovyaz, \\ awatanchik@yandex.ru \\ Daniil 0. Ryabchenko, \\ rd@latat.org
}

\author{
National Research Tomsk Polytechnic University, \\ 30, Lenin avenue, Tomsk, 634050, Russia
}

Natalia V. Krivovyaz, Cand. Sc., associate professor, National Research Tomsk Polytechnic University.

Daniil O. Ryabchenko, postgraduate student, National Research Tomsk Polytechnic University.

The article examines the nature of the creative class, the foundations and prerequisites for the "cultural shift» in the space of the value world of the creative class. The authors have analyzed the preconditions and tendencies of the formation of a system of post-materialistic values - the values of self-expression, well-being, happiness - which are characteristic for the system of the value world, the creative class. The role of innovation as a creative destruction is revealed. The idea of the possibility of measuring creativity in the context of knowledge-based and innovation-based economic growth is announced. The article analyzes the nature of the «displacement» - "tectonic shifts» that occurred in the segments of power and management on the threshold of the XXI century. The authors revealed the priority role of knowledge in the indicated transformations as the status of the dominant resource of the cognitive society. The paper introduces the idea of forming an «intellectual elite» of a cognitive society; signs of elitism are formed as determined by the possession of knowledge. It is shown that within the boundaries of institutions related to intellectual activity, the «new elite» has a monopoly on power and control. But in the world of big politics, one can only talk about the influence of the «new elite» in the areas of expertise, consulting, and procedures for analyzing technically complex decisions.

Key words: Creative economy, creativity, creativity as a capital and a commodity, dimension of creativity, post-materialistic values, innovation, "cultural shift», ethos of the creative class, "post-deficit effect», survival values, values of self-expression, life world of the creative class, imperatives of the innovative era.

\section{REFERENCES}

1. Kollins D. Ot khoroshego $k$ velikomu. Pochemu odni kompanii sovershayut ryvok, a drugie net [From good to great. Why some companies are making a leap and others are not]. Moscow, Mann, Ivanov i Ferber Publ., 2014. 384 p.

2. Collins J. How the mighty fall: and why some companies never give in. New York, Jim Collins, 2009. 240 p.

3. Florida R. Kreativny klass: lyudi, kotorye menyayut budushchee [Creative class: people who change the future]. Moscow, Klassika-XXI Publ., 2007. 421 p.

4. Zankovskiy A.N. Organizatsionnaya psikhologiya [Organizational psychology]. Moscow, Forum Publ., 2009. 646 p.

5. Petrenko V.F. Mnogomernoe soznanie. Psikhosemanticheskaya paradigma [Multidimensional consciousness. Psychosemantic paradigm]. Moscow, Novy khronograf Publ., 2009. 440 p.

6. Endruvayt G. Elity i razvitie: teoriya i issledovaniya vliyaniya elit na protsessy sotsialnopoliticheskogo razvitiya [Elites and development: theory and research on the influence of elites on the processes of social and political development]. Politicheskaya nauka. Elity $v$ sravnitelno- 
istoricheskoy perspektive. Problemno-tematicheskiy sbornik [Political Science. Elites in a comparative historical perspective. Problem-thematic collection]. Moscow, 1998. pp. 10-11.

7. Clarkin L., Holmes J. Enterprise Mashups. Available at: http://msdn.microsoft.com/enus/architecture/bb906060 (accessed 11 January 2021).

8. Roman F., Peterson M., Koster A. The rise of Generation C: how to prepare for the connected generation's transformation of the consumer and business landscape. NY, Strategy + Business, 2011. 8 p.

9. Zankovskiy A.N. Psikhologiya lidera: ot povedencheskoy modeli k kulturno-tsennostnoy paradigme [Leader psychology: from a behavioral model to a cultural and value paradigm]. Moscow, Institute of Psychology of the Russian Academy of Sciences Publ. house, 2011. 295 p.

10. Matsumoto D. Chelovek, kultura, psikhologiya [Man, culture, psychology]. St. Petersburg, PraymEvroznaniye Publ., 2010. 647 p.

11. Vilyakaynen P., Myuller-Eberstayn M. Bez strakha. Lidery biznesa v tsifrovuyu epokhu [Without fear. Business leaders in the digital age]. Moscow, Olimp-Biznes Publ., 2015. 400 p.

12. Tambiyants Yu.G, Shalin V.V. Fenomen politicheskoy elity: problematika opredeleniya sotsialnoy sushchnosti [The phenomenon of the political elite: the problem of defining the social essence]. Obshchestvo i pravo, 2018, no. 4 (66), pp.159-164.

13. Zotkin A.A. Podkhody k opredeleniyu ponyatiya «elita» v rabotakh predstaviteley makiavellistskoy shkoly teorii elit [Approaches to the definition of the concept of «elite» in the works of representatives of the Machiavellian school of the theory of elites]. Uchenye zapiski Krymskogo federalnogo universiteta imeni V.I. Vernadskogo. Sotsiologiya. Pedagogika. Psikhologiya, 2015, vol. 1 (67), no. 4, pp. 3-12.

14. Bassin M., Glebov S., Laruelle M. Between Europe and Asia: the origins, theories, and legacies of Russian Eurasianism. Pittsburgh, University of Pittsburgh press, 2015. 288 p.

15. Al-Dvani M.F.H. Tsennostnye osnovaniya teorii elit [Value foundations of the theory of elites]. Vestnik SPbGU, 2014, series 12, Iss. 2, pp. 146-151.

16. Elin S.P. Kriterii elitnosti v tsennostnom napravlenii razvitiya teorii elit [Elite criteria in the value direction of the development of the theory of elites]. Teoriya i praktika obshchestvennogo razviti$y a, 2014$, no. 10, pp. 37-40.

17. Boynton Andy, Bill Fischer, Bill Bole. The idea hunter: how to find the best ideas and make them happen. San Francisco, CA, Jossey-Bass, 2011. 192 p.

18. Grossman L. 2045: the year man becomes immortal. Available at: https://ru.scribd.com/ document/50201914/2045-The-Year-Man-Becomes-Immortal (accessed 11 January 2021).

19. Zak M.H. Razrabotka znanievoy strategii [Knowledge strategy development]. Upravlenie znaniyami. Khrestomatiya [Knowledge Management. Reader]. St. Petersburg, Vysshaya shkola menedzhmenta Publ., 2008. pp. 189-204.

20. Andreeva T.E. Rabotnik intellektualnogo truda: podkhod k opredeleniyu [Worker of intellectual labor: an approach to definition]. Vestnik Sankt-Peterburgskogo universiteta. Menedzhment, 2007, no. 4 , pp. 32-49.

Received: 20 January 2021. 